\title{
ANALISA PROSES PENYAMBUNGAN HULL CONSTRUCTION DENGAN SUPERSTRUCTURE KAPAL DARI MATERIAL YANG BERBEDA
}

\author{
Sunarso Sugeng, Sulaiman \\ Program Studi D3 Teknologi Perancangan dan Konstruksi Kapal, Departemen Teknologi Industri, \\ Sekolah Vokasi , Universitas Diponegoro Semarang \\ Jl. Prof. Soedarto, SH, Kampus Undip Tembalang, Semarang 50275 \\ Email:
}

\begin{abstract}
Abstrak
Pengelasan saat ini diperlukan terutama di era kemajuan teknologi modern yang berkembang pesat, sehingga dapat diterapkan poda dunia indrustri produksi kapal. Dalam pembuatan kapal patroli polisi harus memiliki kecepatan yang baik tanpa mengesampingkan kekuatan dari kapal tersebut. Maka dari itu dikembangkan teknologi pembuatan kapal material aluminium dan baja .Pada Kapal Patroli Polisi Kelas A1 63 meter digunakan antara baja dan aluminium menggunakan proses pengelasan GTAW pada pengelasan aluminium dengan bimetal dan FCAW, SMAW pada pengelasan baja dengan bimetal karena setiap bahan memiliki komponen yang berbeda sehingga pengelasan yang berbeda digunakan. Bimetal merupakan alat yang terdiri dari dua logam yang berbeda nilai koefisien muai panjang atau yang berbeda kecepatan pemuaiannya, direkatkan menjadi satu. Kebutuhan bimetal untuk proses penyambungan Kapal Patroli Polisi - Kelas A1 63 meter adalah 55 batang.
\end{abstract}

Kata Kunci : “Konstruksi”, "Pengelasan”, “Bimetal”.

\section{Pendahuluan}

Indonesia merupakan negara kepulauan di dunia dengan luas perairan lebih besar dari pada luas daratan, maka dari itu Indonesia disebut sebagai Negara Maritim.Indonesia memiliki 17.499 pulau dari Sabang hingga Merauke. Luas total wilayah Indonesia adalah 7,81 juta $\mathrm{km} 2$ yang terdiri dari 2,01 juta $\mathrm{km} 2$ daratan, 3,25 juta $\mathrm{km} 2$ lautan, dan 2,55 juta $\mathrm{km}^{2}$ Zona Ekonomi Eksklusif (ZEE). Sebagai negara kepulauan terbesar di dunia, keindahan bahari dan hasil laut yang dimiliki Indonesia tentu memiliki kualitas terbaik. Mulai pulau yang cantik akan isi lautnya seperti terumbu karang dan tumbuhan laut. Kekayaan laut yang dimiliki membuat perhatian masyarakat luar negeri menjadi meyukai hasil laut Indonesia.

Hal ini tentu menjadi daya tarik tersediri bagi negara asing atau orang yang tidak bertanggung jawab yang memungkinkan melakukan tindak kejahatan terhadap Indonesia. Masalah yang muncul seperti ilegal fishing, masalah tapak batas negara, sampai pada penyuludupan barang - barang ilegal dari luar negeri, harus lebih diperhatikan demi menjaga eksistensi kedaulatan laut Indonesia. Upaya serta komitmen pemerintah dalam hal menjaga kedaulatan laut Indonesia melalui pemberantasan ilegal fishing serta pengamanan wilayah-wilayah laut terluar Indonesia sangat diperlukan. Agar terwujudnya negara sebagai poros maritim dunia, memungkinkan Indonesia untuk bekerja ekstra keras dalam bentuk pengamanan dan melindungi sumber daya di laut.

Maka dari itu perlu lebih banyak lagi transportasi laut yang dibangun, salah satunya dengan pembangunan Kapal Patroli Polisi - Kelas A1 - 63 meter diharapkan ke depannya dapat meningkatkan kekuatan dan kemampuan Bakamla RI, khususnya bagi kebutuhan unsur operasional dalam mengemban tugasnya melakukan patroli keamanan dan keselamatan di wilayah perairan Indonesia dan wilayah yurisdiksi Indonesia. Dalam pembuatan Kapal Patroli Polisi harus memiliki kecepatan yang baik tanpa mengesampingkan kekuatan dari kapal tersebut.Maka dari itu dikembangkan teknologi pembuatan kapal material aluminium dan baja yang memiliki kecepatan. 
Tujuan dari penelitian ini adalah untuk mengetahui :

a. Cara penyambungan hull construction dengan superstructure dengan material yang berbeda.

b. Pengaruh penggunaan bimetal pada hasil pengelasan hull construction dengan superstructure.

\section{Metode Penilitian}

\subsection{Alumunium}

Aluminium adalah golongan dari jenis logam Non-Ferrous yang memiliki kelebihan tertentu dibandingkan logam lainnya yang dipergunakan dalam dunia industri, aluminium merupakan logam ringan, mempunyai ketahanan korosi yang baik dan hantaran listrik yang baik dan sifat-sifat baik lainya sebagai sifat logam, selain itu aluminium juga mempunyai sifat mampu bentuk (Wrought alloy) dimana paduan aluminium ini dapat dikerjakan atau diproses baik dalam pengerjaan dingin maupun pengerjaan panas (dengan peleburan), lihat pada gambar1. [2] Karena sifat-sifat inilah maka banyak dilakuan penelitian untuk meningkatkan kekuatan mekaniknya, diantaranya dengan menambahkan unsurunsur seperti: $\mathrm{Cu}, \mathrm{Mg}, \mathrm{Si}, \mathrm{Mn}, \mathrm{Zn}, \mathrm{Ni}$, dan sebagainya, baik dicampur secara satu persatu maupun secara bersama-sama, bahanbahan tersebut juga memberikan sifat-sifat baik lainya seperti ketahanan korosi, ketahanan aus, koefisien pemuaian rendah. Material ini dipergunakan dalam bidang yang sangat luas, bukan saja untuk peralatan rumah tangga tetapi juga dipakai untuk keperluan material pesawat terbang, mobil, kapal laut, kontruksi dan sebagainya.

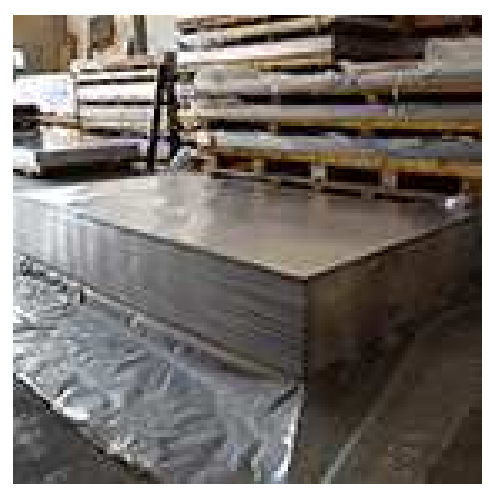

Gambar 1. Lembaran Pelat Aluminium

Aluminium murni adalah logam yang lunak, tahan lama, ringan, dan dapat ditempa dengan penampilan luar bervariasi antara keperakan hingga abu-abu, tergantung kekasaran permukaannya. Kekuatan tarik Aluminium murni adalah $90 \mathrm{MPa}$, sedangkan aluminium paduan memiliki kekuatan tarik berkisar hingga $600 \mathrm{MPa}$. [3] Aluminium memiliki berat sekitar satu pertiga baja, mudah ditekuk, diperlakukan dengan mesin, dicor, ditarik (drawing) dan diekstrusi. Resistansi terhadap korosi terjadi akibat fenomena pasivasi, yaitu terbentuknya lapisan aluminium oksida ketika aluminium terpapar dengan udara bebas. Lapisan aluminium oksida ini mencegah terjadinya oksidasi lebih jauh.

Aluminium yang digunakan pada pembuatan Kapal Patroli Polisi - Kelas A1 - 63 meter Aluminium terdiri dari beberapa kelompok yang dibedakan berdasarkan paduan penyusunnya. Penambahan paduan ini akan menghasilkan sifat yang berbeda pula. Yang digunakan pada Kapal Patroli Polisi 63 meter adalah alumunium 5083 yang merupakan paduan aluminium dengan magnesium $(\mathrm{Mg})$, paduan ini memiliki sifat tidak dapat diperlakukan-panas, tetapi memiliki sifat baik dalam daya tahan korosi terutama korosi oleh air laut dan sifat mampu las $\mathrm{Al}-\mathrm{Mg}$ banyak dipakai untuk konstruksi umum termasuk konstruksi kapal.Alumunium seri 5083 termasuk dalam golongan paduan alumunium seri 5xxxx, yaitu $\mathrm{Al}-\mathrm{Mg}$ [1].

Paduan dalam sistem ini mempunyai kekuatan kurang sebagai barang tempaan dibandingkan dengan paduan-paduan 
lainnya, tetapi sangat liat, sangat baik mampu bentuknya untuk penempaan, ekstrusi dan sangat baik untuk mampu bentuk yang tinggi pada temperatur biasa.

Ukuran aluminium pada Kapal Patroli Polisi - Kelas A1 - 63 meter :

1. $4 \mathrm{~mm} \times 1500 \mathrm{~mm}$ x $6000 \mathrm{~mm}$ - digunakan pada kulit bangunan atas

$2.5 \mathrm{~mm} \times 1500 \mathrm{~mm} \times 6000 \mathrm{~mm}$ - digunakan pada kulit bangunan atas

3. $10 \mathrm{~mm} \times 1500 \mathrm{~mm} \times 6000 \mathrm{~mm} \mathrm{-}$ digunakan pada gading bangunan atas

4. $12 \mathrm{~mm} \mathrm{x} 1500 \mathrm{~mm}$ x $6000 \mathrm{~mm} \mathrm{-}$ digunakan pada gading bangunan atas

Keunggulan aluminium :

- Bahan yang ringan

- Tahan terhadap korosi air laut (Aluminium jenis Marine Grade)

- Mempunyai nilai jual tiggi saat kondisi afkir

- Perawatan mudah

- Kuat dan tahan benturan ataupun benda Tajam

- Tahan Lama

- Secara estetika tanpa harus dicat sudah terlihat indah

Kekurangan aluminium :

- Harga mahal

- Agak susah di bentuk untuk kapal - kapal yang butuh desain agak ekstrim

- Butuh tenaga kerja khusus dalam pengerjaannya

- Tidak bisa di gabungkan dengan material logam yang mempunyai beda jenis (bisa mempercepat korosi kimiawi)

- Jika terjadi kerusakan tidak sembarang orang bisa memperbaiki.

Jenis aluminium Marine Grade :

- Main alloying element magnesium $(\mathrm{Mg})$ (marine grade alloys)

- Aluminium Marine Grade 5052 (digunakan untuk lambung pada tipe kapal yang beroperasi dengan kondisi berkarang)

- Aluminium Marine Grade 5083

- Aluminium Marine Grade 5086

- Aluminium Marine Structure Grade 6061

\subsection{Baja}

Baja adalah logam paduan dengan besi ( $\mathrm{Fe})$ sebagai unsur dasar dan karbon (C) sebagai unsur paduan utamanya. Kandungan karbon dalam baja berkisar antara 0,2 \% hingga 2,1 $\%$ berat sesuai grade-nya [10]. Fungsi karbon dalam baja adalah sebagai unsur pengerasan pada kisi kristal atom besi. Baja karbon adalah baja yang mengandung karbon lebih kecil $1,7 \%$, sedangkan besi mempunyai kadar karbon lebih besar dari $1.7 \%$. Baja mempunyai unsur-unsur lain sebagai pemadu yang dapat mempengaruhi [3]. Material baja unggul jika ditinjau dari segi kekuatan, kekakuan dan daktilitasnya. Jadi tidak mengherankan jika di setiap proyek-proyek konstruksi bangunan (jembatan atau gedung) maka baja selalu ditemukan, meskipun tentu saja volumenya tidak harus mendominasi. Tinjauan dari segi kekuatan, kekakuan dan daktilitas sangat cocok dipakai mengevaluasi struktur yang diberi pembebanan [14] Tetapi perlu diingat bahwa selain kondisi tadi akan ada pengaruh lingkungan yang mempengaruhi kelangsungan hidup struktur bangunannya [11]. Jadi pada suatu kondisi tertentu, suatu bangunan bahkan dapat mengalami kerusakan meskipun tanpa diberikan beban sekalipun (belum berfungsi). Jadi ketahanan bahan material konstruksi terhadap lingkungan sekitarnya adalah penting untuk diketahui agar dapat diantisipasi baik.

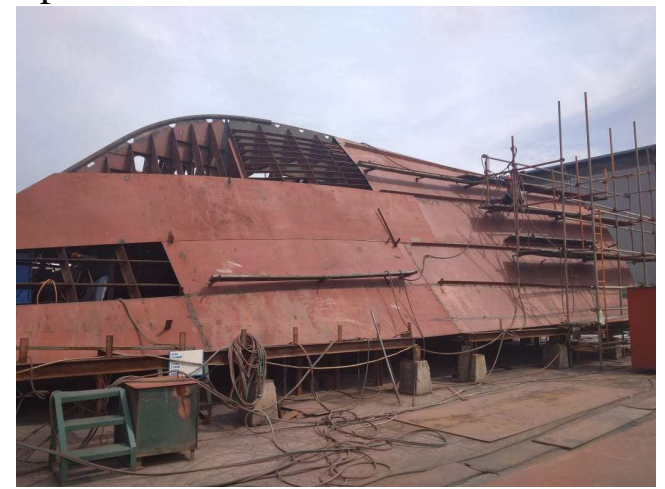

Gamabr 2. Penggunaan Baja pada konstruksi kapal

Kelebihan material baja dibandingkan material beton atau kayu adalah karena 
buatan pabrik, yang tentunya mempunyai kontrol mutu yang baik, lihat pada gambar 2 . Oleh karena itu dapat dipahami bahwa kualitas material baja yang dihasilkannya relatif homogen dan konsisten dibanding material lain, yang berarti juga lebih dapat diandalkan mutunya [4].

Di sisi lain karena merupakan hasil produk industri, agar prosesnya menguntungkan harus diusahakan mencapai kondisi optimum. Untuk itu diperlukan suatu kuantitas tertentu yang terkesan relatif monoton serta tidak mudah dibuat variasinya. Itulah pentingnya dibuat standarisasi bentuk profil [9] . Dari tabel profil baja yang ada terlihat banyak sekali profil yang tersedia, tetapi dalam kenyataannya jika peminatnya relatif sedikit maka profil yang jarang dipakai tentunya tidak diproduksi banyak. Jadi akhirnya tidak semua profil pada tabel dapat dipilih [5]. Hanya profil-profil tertentu yang memang umum (banyak) digunakan. Hal ini perlu diketahui insinyur perencana konstruksi baja, jangan hanya berpedoman teoritis hitungan, karena kalau sampai mengubah profil rencana dengan profil tersedia, kemungkinan berubah pula detail sambungan yang dibuat. Jika ini tidak dipikirkan waktu dapat terbuang sia-sia.Tidak ada jaminan bahwa lokasi pabrik baja akan berdekatan dengan proyek atau bengkel fabrikasi, sehingga panjang profil baja ditentukan oleh kemampuan kendaraan transportasi pengangkut (truk atau kapal) dan jalur transportasi (darat atau air) yang akan dilaluinya [13].

\subsection{Bimetal}

Bimetal adalah alat yang terdiri dari dua logam yang berbeda nilai koefisien muai panjangnya atau yang berbeda kecepatan pemuaiannya, direkatkan menjadi satu. Keping Bimetal sengaja dibuat memiliki dua buah keping logam karena kepingan ini dapat melengkung jika terjadi perubahan suhu, lihat pada gambar 3. Prinsipnya, apabila suhu berubah menjadi tinggi, keping bimetal akan melengkung ke arah logam yang keoefisien muainya lebih rendah, sedangkan jika suhu menjadi rendah, keping bimetal akan melengkung ke arah logam yang keofisien muainya lebih tinggi [15]. Logam dengan koefisien muai lebih besar (tinggi) akan lebih cepat memanjang sehingga kepingan akan membengkok (melengkung) sebab logam yang satunya lagi tidak ikut memanjang. Biasanya keping bimetal ini terbuat dari logam yang koefisien muainya jauh berbeda, seperti besi dan tembaga, baja dan aluminium [6] .

Bimetal juga disebut bimetal panas. Karena koefisien ekspansi termal dari lapisan komponen berbeda, ketika suhu berubah, deformasi lapisan aktif lebih besar dari deformasi lapisan pasif, sehingga seluruh bimetal ditekuk ke arah sisi lapisan pasif. Kemudian, kelengkungan material komposit berubah menjadi deformasi. Di antara mereka, semakin tinggi koefisien ekspansi disebut lapisan aktif; semakin rendah koefisien ekspansi disebut lapisan pasif [17]. Namun, dengan perluasan bidang aplikasi bimetal dan kemajuan teknologi ikatan, tiga, empat, dan lima lapis bimetal telah muncul di zaman modern. Bahkan, setiap kombinasi bahan yang berubah bentuk tergantung pada perubahan suhu masih dikenal hari ini sebagai bimetal panas.

Bahan lapisan aktif terutama meliputi paduan mangan-nikel-tembaga, paduan nikelkromium-besi, paduan nikel-mangan-besi dan nikel, dll; bahan lapisan pasif terutama paduan nikel-besi, dan kandungan nikel adalah 34-50\% [7] .

Berikut merupakan sifat-sifat bimetal atau cara kerja bimetal :

1) Jika bimetal dipanaskan, maka bimetal akan melengkung ke arah logam yang memiliki koefisien muainya lebih kecil.

2) Sebaliknya, jika bimetal didinginkan, maka bimetal akan melengkung ke arah logam yang memiliki koefisien muainya lebih besar. 


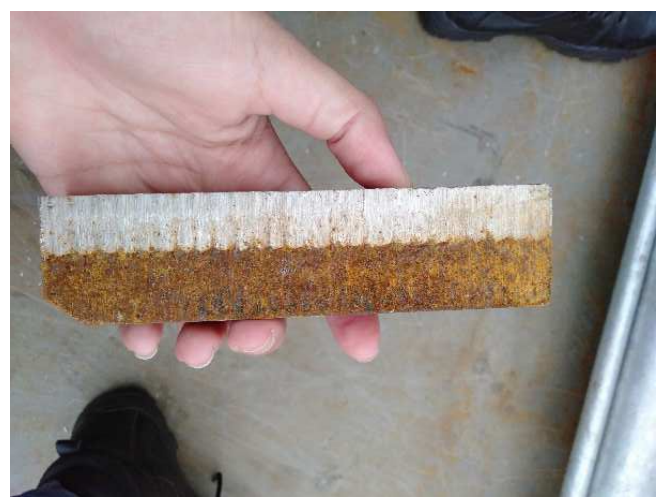

Gambar 3. Bimetal Strip

\section{Hasil Dan Pembahasan}

Penerapan proses penyambungan hull construction dengan superstructure kapal dengan material yang berbeda ini dilakukan dengan pertimbangan :

- Menerapkan teknologi perbedaan berat material sehingga diharapkan dapat meningkatakan kecepatan laju kapal.

- Lokasi penyambungan material berada di galangan kapal dengan peralatan pengelasan yang cukup lengkap.

Data Kapal Patroli Polisi - Kelas A1 -63 meter :

$\begin{array}{ll}\text { Length Over All (LOA) } & : 63,00 \mathrm{M} \\ \text { Length Perpendicular (LPP) } & : 58,274 \mathrm{M} \\ \text { Breadth (B) } & : 8,2 \mathrm{M} \\ \text { Height (T) } & : 4,55 \mathrm{M} \\ \text { Draft (d) } & : 2,00 \mathrm{M} \\ \text { Bimetal } & : \text { Bimetalic Strip }\end{array}$

Bimetal

: Bimetallic Strip

Aluminium $20 \mathrm{~mm}$ x 34,5 mm x $3800 \mathrm{~mm}$

\subsection{Pengelasan Pada Bimetal Dengan GTAW}

Cara Pengelasan yang digunakan pada penyambungan aluminium dengan bimetal yaitu pengelasan GTAW (Gas Tungsten Arc Welding) atau MIG/TIG dengan kawat las Grade 5356 Aluminium Alloy (diameter 1,2 $\mathrm{mm}$ ). Banyak yang tidak diketahui orang bahwa pengelasan aluminium harus dilakukan di dalam ruangan, selain itu karena memiliki tingkat kesulitan yang berbeda dengan baja, pengelasan aluminium lebih baik dilakukan oleh ahlinya agar tidak menimbulkan deformasi saat pengelasan. Pada pengelasan antara aluminium dengan bimetal harus diberi jarak sekitar $2-3 \mathrm{~mm}$ agar tidak mengalami pemuaian [8] .

Gas tungsten arc welding (GTAW) adalah proses las busur yang menggunakan busur antara tungsten elektroda (non konsumsi) dan titik pengelasan, lihat pada gambar 4 . Proses ini digunakan dengan perlindungan gas dan tanpa penerapan tekanan. Proses ini dapat digunakan dengan atau tanpa penambahan filler metal. GTAW telah menjadi sangat diperlukan sebagai alat bagi banyak industri karena hasil las berkualitas tinggi dan biaya peralatan yang rendah.

Las listrik TIG (Tungsten Inert Gas = Tungsten Gas Mulia) menggunakan elektroda wolfram yang bukan merupakan bahan tambah lihat pada gambar 4 . Busur listrik yang terjadi antara ujung elektroda wolfram dan bahan dasar merupakan sumber panas, untuk pengelasan. Titik cair elektroda wolfram sedemikian tingginya sampai $3410^{\circ}$ $\mathrm{C}$, sehingga tidak ikut mencair pada saat terjadi busur listrik.Tangkai listrik dilengkapi dengan nosel keramik untuk penyembur gas pelindung yang melindungi daerah las dari luar pada saat pengelasan.Sebagian bahan tambah dipakai elektroda tanpa selaput yang digerakkan dan didekatkan ke busur yang terjadi antara elektroda wolfram dengan bahan dasar. Sebagi gas pelindung dipakai gas inert seperti argon, helium atau campuran dari kedua gas tersebut yang pemakainnya tergantung dari jenis logam yang akan dilas.

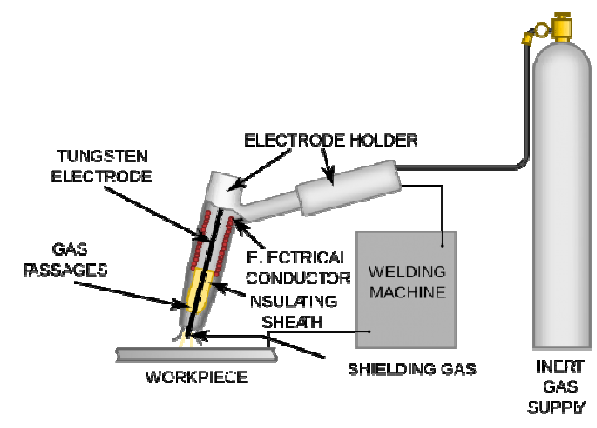

Gambar 4. Skema Pengelasan GTAW 


\subsection{Pengelasan Pada Bimetal Dengan FCAW}

Pengelasan yang digunakan pada penyambungan baja dengan bimetal terdiri dari 2 macam yaitu pengelasan FCAW (Flux Core Arc Welding) dengan kawat las Grade E60 Tipe Approval BKI (roll) dan SMAW (Shielded Metal Arc Welding) dengan kawat las Grade 6013 Tipe Approval BKI (stick). Sama halnya dengan pengelasan aluminium dengan bimetal, pengelasan pada baja dengan bimetal harus diberi jarak $2-3 \mathrm{~mm}$ agar tidak mengalami pemuaian [12] .

Pengertian Pengelasan FCAW adalah Las busur listrik yang kawat lasnya terdapat fluk (pelindung inti tengah). Pada gambar 5, Las FCAW adalah kombinasi antara proses pengelasan GMAW, SMAW dan SAW. Dalam pengelasan FCAW ini sumber energi menggunakan arus listrik DC atau AC yang diambil dari pembangkit listrik atau melalui trafo dan atau rectifier.Pengelasan FCAW merupakan salah satu jenis las listrik yang proses kerjanya memasok filler elektroda atau kawat las secara mekanis terus menerus ke dalam busur listrik, lihat pada gambar 5 .

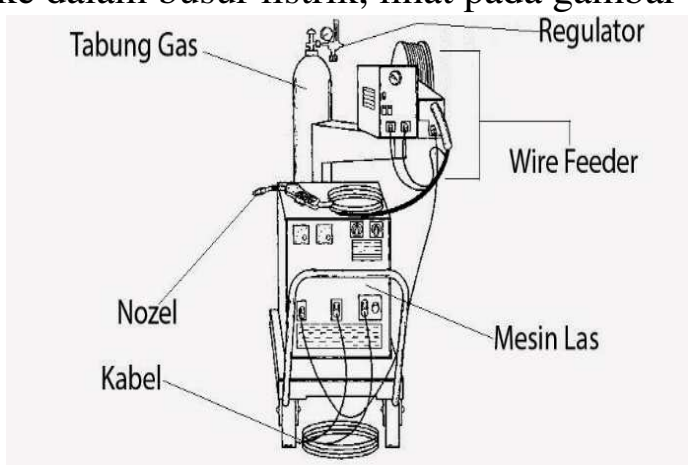

Gambar 5. Alat untuk Pengelasan FCAW

Kawat las atau Elektroda yang digunakan untuk pengelasan FCAW terbuat dari logam tipis yang digulung cylindrical kemudian dalamnya diisi dengan flux yang sesuai dengan kegunaannya.

Proses Pengelasan FCAW ini sebenarnya sama dengan pengelasan GMAW, namun membedakan adalah kawat las atau elektrodanya yang berbentuk tubular yang berisi fluks sedangkan GMAW berbentuk Solid, lihat gambar 6.

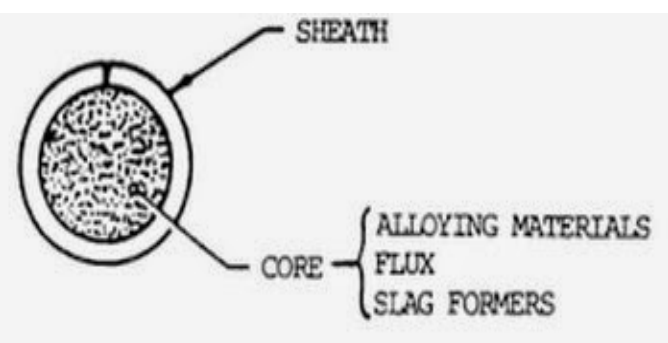

Gambar 6. Potongan kawat Las FCAW Tubular

Berdasarkan metode pelindung, Pengelasan FCAW dapat dibedakan menjadi 2:

a. Self shielding FCAW (Pelindungan sendiri), yaitu merupakan proses melindungi logam las yang mencair dengan menggunakan gas dari hasil penguapan atau reaksi dari inti fluks.

b. Gas shielding FCAW (perlindungan gas) adalah perlindungan dengan dual gas, yaitu melindungi logam las yang mencair dengan menggunakan gas sendiri juga ditambah gas pelindung yang berasal dari luar sistem.

\subsection{Pengelasan Pada Bimetal Dengan SMAW}

Proses pengelasan SMAW (Shield Metal Arc Welding) yang juga disebut Las Busur Listrik adalah proses pengelasan yang menggunakan panas untuk mencairkan material dasar atau logam induk dan elektroda (bahan pengisi) lihat gambar 7 . Panas tersebut dihasilkan oleh lompatan ion listrik yang terjadi antara katoda dan anoda (ujung elektroda dan permukaan plat yang akan dilas) [8] .

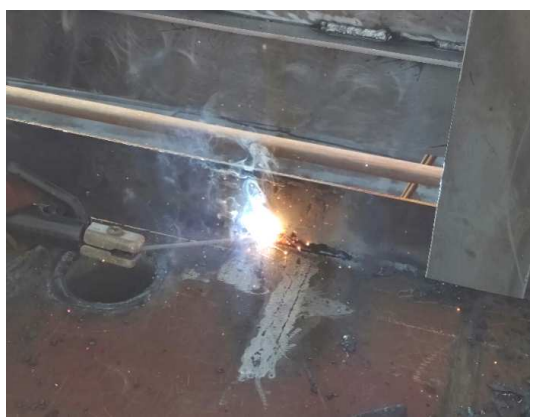

Gambar 7. Pengelasan dengan SMAW pada bimetal 
4.4 Estimasi Penggunaan Bimetal

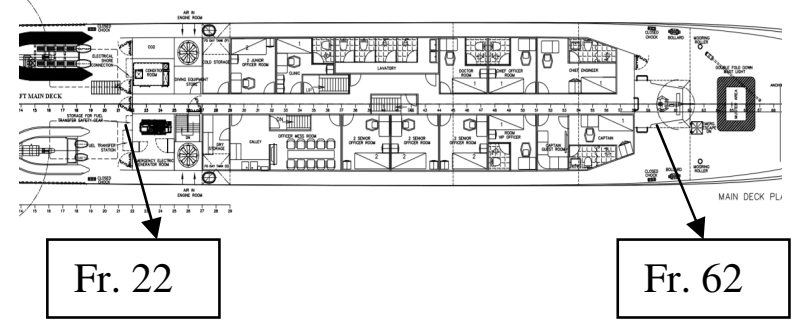

Gambar 8. General Arrangement

Dari Gambar 8, didapatkan estimasi penggunaan Bimetal untuk Kapal Patroli Polisi - Kelas A1 - 63 Meter kurang lebih 60 buah bimetal utuh.

Cara menghitung estimasi bimetal :

1. Dibutuhkan gambar General Arrangemet dengan format autocad atau hard file pada kertaS A1.

2. Hitung kebutuhan bimetal pada kulit terluar dari Superstructure, mulai dari samping kanan, samping kiri, depan dan belakang hingga sekat aluminium yang membutuhkan bimetal.

Dapat dihitung pada gambar bahwa penggunaan bimetal pada sisi kanan, kiri, dan gangwaydimulai dari frame 22 sampai dengan 62, apabila panjang tiap frame $800 \mathrm{~mm}$, maka :

Total Bimetal $=309,2 \mathrm{~m}: 6 \mathrm{~m}$ (panjang bimetal) $\quad=52,53$ buah

Dibulatkan menjadi 55 s/d 60 bimetal.

\section{Kesimpulan}

Bimetal merupakan alat yang terdiri dari dua logam yang berbeda nilai koefisien muai panjang atau yang berbeda kecepatan pemuaiannya, direkatkan menjadi satu. Yang memiliki keistimewaan dapat menyambungkan dua logam yang berbeda jenis, seperti penyambungan aluminium dan baja pada Kapal Patroli Polisi - Kelas A1 -63 meter. Dengan pendekatan perhitungan panjang area yang akan dilakukan penyambungan maka didapatkan kebutuhan $309,2 \mathrm{~m}$ atau 52,53 buah bimetal.
Dalam penyambungan Hull Construction dengan Superstructure diperlukan proses pengelasan yang berbeda, bagian Hull Construction yang terbuat dari material baja disambung dengan pengelasan SMAW dan FCAW, sedangkan pada Superstructure yang terbuat dari material aluminium diperlukan pengelasan khusus yaitu GTAW. Penyambungan Hull Construction dengan Superstructure yang terbuat dari material yang berbeda diperlukan bimetal untuk mengurangi resiko deformasi.

\section{Daftar Pustaka}

- Biro Klasifikasi Indonesia . 2018. Rules for The Clasification and Construction of Seagoing Stel Ships, Volume II, Rules For Hull, Edition 2018. BKI. Jakarta

- Callister Jr, William, D. 1994. Material Science and Engineering, 3rd edition John Wiley \& Sons, Inc. Hoboken, New Jersey.

- Caridis, P.A dan Mrina. C., 1995, Inspection, Repair and Maintenance of Ship Structure, Witherby \& CO. LTD, London

- Djaya, I,K. 2008. Teknik Konstruksi Kapal Baja jilid 2.Jakarta : BSE

- E. Paul DeGarmo, JT. Black, Rodald A. Kohser, "Materials And Processes In Manufacturing”, John Wiley \& Sons, 2003.

- Fontana, Mars G, 1986, Corrosion Engineering, 3th Edition, Mc Graw Hill Book Co.,New York

- P. R. Permana, "Analisis Kekuatan Struktur dan Estimasi Fatigue Life Pada Konstruksi Container Crane Tipe RTG Berkapasitas SWL 35 Ton," Surabaya, 2015

- G. J. K. N. Richard and S. Budynas. 2011. Mechanical Engineering Design. New York: Mc Graw Hill.

- Kim et al., 2014. Welding deformation analysis based on improved equivalent strain method 
considering the effect of • Sulaiman, Julianto Eko.2015. Perubahan temperature gradients .Int. J. Nav. Archit. Ocean Eng., 7 (1) (2014), pp. 157-173

- Lancaster J.F. 1999, Metallurgy of Welding 6th Edition. USA: Woodhead Publishing. Nilai Kekerasan Pelat Baja Kapal Dengan Perlakuan Bending Line Heating. TEKNIS Volume 10 no 2 hal 76-80.

- Tsai, Tai Ming, 1995, Protection of Steel Using Aluminum Sacrificial Anodes

- Sasono A,J, Sulaiman, Darmanto S, Proyono E. 2014. Analisa Perbandingan Laju Korosi lambung kapal dengan Aplikasi Paduan Alumunium. TEKNIS Volume 8 no 2 hal 28-34.

- Shipeng et al., 2013. An integrated method for block assembly sequence planning in shipbuilding .Int. J. Adv. Manuf. Tech., 69 (2013), pp. 1123-1135

- Singh R . 2015. Applied Welding Engineering@ @nd Edition. Butterworth-Heinemann. USA in Artificial Seawater, Journal of Marine Science and Technology, Volume 4, No.1, Tahun 1995, halaman $17-21$

- Y.S. Ha 2011 . A study on weldment boundary condition for elastoplastic thermal distortion analysis of large welded structures J. KWJS, 29-4 (2011), pp. 48-53

- Zhang et al., 2002. Automated sequencing and sub-assembly detection in automobile body assembly planning. J. Mater. Process. Technol., 129 (13) (2002), pp. 